\title{
$\widehat{A}$ Madridge \\ madridge Journal of Case Reports and Studies \\ interconnectin
}

Short Communication

Open Access

\section{Considerations in the care of the Hemiplegic Stroke Patient}

\author{
Ingrid Brenner* \\ Trent/Fleming School of Nursing, Trent University, 1600 West Bank Drive, Peterborough, Canada
}

\section{Article Info}

\author{
*Corresponding author: \\ Ingrid Brenner \\ Trent/Fleming School of Nursing \\ Trent University \\ 1600 West Bank Drive \\ Peterborough \\ Canada \\ Tel: 705-748-101 ext. 7253 \\ E-mail: ibrenner@trentu.ca
}

Received: June 26, 2018

Accepted: June 28, 2018

Published: July 1, 2018

Citation: Brenner IK. Considerations in the Care of the Hemiplegic Stroke Patient. Madridge J Case Rep Stud. 2018; 2(1): 38-40. doi: 10.18689/mjcrs-1000110

\section{Copyright: (c) 2018 The Author(s). This work is licensed under a Creative Commons Attribution 4.0 International License, which permits unrestricted use, distribution, and reproduction in any medium, provided the original work is properly cited.}

Published by Madridge Publishers

\begin{abstract}
Limited experience in the treatment and care of hemiplegic stroke patients can make nursing care challenging. In fact, care of such patients can sometimes require a substantial learning curve. The purpose of this short communication is to share issues that health care providers may encounter in the care of hemiplegic stroke patients and proposes strategies to minimize these challenges. Experience with care of a hemiplegic stroke patient has demonstrated that special attention should be directed towards maintaining adequate hydration and promoting good incontinence care practices. As dehydration and ineffective incontinence care can contribute to substantial illness (e.g., development of sepsis) in these patients.
\end{abstract}

Keywords: Hemiplegic stroke; Reduced level of consciousness; Arm or facial weakness; Poor dental status.

\section{Introduction}

Depending upon the site and extent of lesion, stroke patients present both common and unique characteristics which can make nursing care challenging. Personal experience with the care of a hemiplegic stroke patient has led to the formulation of strategies that can be useful to nurses, personal support workers and family members who care for severe stroke patients. Thus, taking the perspective of activities of daily living (diet, continence care, physical activity and sleep), this short communication is intended to provide those who care for stroke patients with factors to consider when providing their care.

\section{Diet}

Feeding and Food. Over $80 \%$ of stroke patients residing in long-term care have some form of dependence on feeding, with $22.5 \%$ requiring total or extensive assistance [1]. Moreover, 25\% suffer dysphagia (impaired or difficulty swallowing) making them susceptible to aspiration pneumonia and 30\% experience poor food intake and/or appetite [1]. As a result of this and several other factors related to their stroke (e.g., reduced level of consciousness, arm or facial weakness, poor dental status, lack of teeth or no dentures and limited mobility) many stroke patients are malnourished [2]. A variety of dysphagia treatment programs which include swallow therapy, compensatory strategies and the alteration of one's diet have been shown to be effective in preventing aspiration pneumonia from developing [3].

Strategies to improve diet and feeding include a dedicated care provider who takes care of (or oversees) the preparation of the food and assists with the patient's intake of food. For the patient with dysphagia, food needs to be either strained, pureed or sliced very thinly. This requires a blender for the preparation of most meals. Eating out poses 
difficulties and limits food intake to soft, pureed-type foods such as mashed potatoes, soups (which may need to be thickened) and yogurt unless the chef is prepared to puree the meal. Special techniques to assist the dependant stroke patient with swallowing included placing the fork or spoon far back in the mouth and spoon-feeding liquids instead of allowing the patient to drink from a glass [1].

Patients recovering from a stroke should follow food guidelines adapted for cardiovascular health. A Mediterranean diet (which consists of fruits, vegetables, fish and beneficial oils such as olive and canola oil) is recommended for the prevention of stroke and its reoccurrence [4]. Other strategies such as avoiding egg yolk, decreasing the consumption of animal flesh and increasing vitamin $B_{12}$ and vitamin $E$ are recommended to promote cardiovascular health. Typical meals may include the following: for breakfast - boiled or scrambled eggs (include only the egg whites), cream of wheat, yogurt, thickened orange or apple juice, for lunch - soups and sandwiches and for dinner - baked or broiled chicken or fish, mashed potatoes, asparagus and carrots are good options.

Hydration One of the largest challenges in the care of the stroke patient is the maintenance of adequate hydration status. Twenty to thirty percent of the elderly experience water-loss dehydration [5]. Older stroke patients are even more vulnerable to dehydration, especially if they are totally dependent upon assistance with their fluid intake. In one study, $62 \%$ of stroke patients admitted to hospital were dehydrated at some point in time during their stay [6].

There are several reasons for the increased susceptibility of elderly stroke patients to succumb to dehydration. First, older individuals become less effective at concentrating their urine. Kidney function deteriorates and fluid reserve is smaller [5]. The vasopressin (antidiuretic hormone [ADH]) response is impaired and there is a reduction in the presence of aquaporins (water channel proteins) present in the medulla of the kidney. Thus, if fluid output is monitored (for example, through assessing urine output via an indwelling catheter or the weight of the incontinence pad) to assess hydration state it could give misleading feedback. Secondly, thirst sensation is diminished in the older stroke patient, decreasing the desire to drink. Finally, many stroke patients experience dysphagia following their stroke and require fluids that are supplemented with a thickening powder. However, dysphagic patients who receive thickened fluids, tend to fall short on their daily fluid intake requirements [7]. Ready-prepared (pre-thickened) fluids (vs powder-thickened fluids) tends to improve oralfluid intake [8], perhaps by creating the correct consistency making the beverage more palatable. Although, thickening of the fluid changes the consistency (makes it thicker) as well as the taste of the liquid, it helps prevent aspiration pneumonia.

Strategies to overcome dehydration would be to have a regimented routine and a set goal in mind. Godfrey et al., [9] recommend $1500 \mathrm{~mL}$ intake of fluids daily. One routine that works well is to give lots of fluid in the morning when medications are taken, a 1-2 drink with each meal and one drink at morning and afternoon snack and bed-time.

\section{Incontinence care}

Urinary and bowel incontinence, defined as involuntary leakage of urine or stool, respectively is common amongst stroke patients. Care providers must ensure due diligence when providing perineal care to prevent skin breakdown and the development of urinary tract infections. Bacteria in stool has the potential for triggering skin breakdown and the development of sores and exposed areas in the perineal region. Regular change of incontinence pads and thoroughly cleaning the area with soap and water can minimize these risks. Personal experience has demonstrated that four changes/cleanings per day plus application of a protective coating such as dimethicone cream (in cream form or barrier cream cloths) is effective in minimizing these risks. Thick incontinence pads that are indicated for night-time use plus an adult diaper covering are effective for fluid absorption in daytime and at night, minimizing any leakage.

If stool comes in contact with the urethra, there is the potential for a urinary tract infection to develop. Typical early indications of a urinary tract infection such as pain in the urethra or pain with voiding may not be noticed or expressed by the stroke patient. Altered level of consciousness, confusion and the development of fever are indicators that the nurse or care provider should be aware of. Interestingly, during the development of fever, stroke patients may develop rigors that effect only one side of the body only (i.e., the non-paralyzed side). Clinicians may sometimes confuse this sign with indications of another stroke that may be occurring. If not noticed soon enough, the patient may develop sepsis which could be life threatening. A simple way to prevent UTIs from developing is to encourage the patient lots of fluids.

\section{Sleep and positioning}

Stroke patients speed a substantial amount of time sleeping. Part of this is due to the brain healing and the other part is due to boredom and limited functional ability. As a result of their limited mobility, patients spend the majority of time in a wheel-chair and the other part in bed. Positioning becomes important to help limit the development of complications such as spasticity and contractures in the hemiplegic patient. Nurses play a central role in helping patients with this. The most commonly advocated strategy is to place patients in a reflex-inhibiting posture [10]. Patients can be placed on the affected side, the unaffected side as well as supine on the back and in the sitting position (in bed or in a wheel chair). Turning the patient can be facilitated by having the patient lay on their back in the supine position, bend both knees and turn the whole body as a unit, using both knees as the pivot point. It should be noted that a major drawback to lying on the unaffected side is that affected limbs will develop edema due to limited venous return through an ineffective muscle pump.

\section{Physical Activity}

Although hemiplegic individuals are severely limited in their movement, care providers should be aware that regular exercise can be done through passive exercise training. 
However, limited research is available on this type of intervention. Brenner [11] described a case study of promoting physical activity at home in a hemiplegic individual. This involved using a passive cycle ergometer which was motorized to induce movement. Cycling began at $5 \mathrm{~min}$ per day and progressively increased to $45 \mathrm{~min}$ per day, over 3 months. Positive adaptations were noticed for such an intervention including improvement in motor function and cognitive ability.

\section{Limitations}

The recommendations made in this short communication are based upon a case study involving an elderly (94 yr old), stroke-induced hemiplegic male patient. Due to the limited sample size and focus on the results of care of only one individual, the results may not necessarily be generalized to all stroke patients, however, it is hoped that the strategies proposed may be useful for those who care for hemiplegic stroke patients in the future.

\section{Conclusions}

Although stroke patients will vary on their presentation, location of lesion in the brain and motor function, there are some basic considerations/strategies that should be kept in mind before providing care. Personal experience has indicated that one if the most important care issues is to maintain proper hydration state, without which, the patient becomes lethargic and stroke symptoms become exacerbated. Secondly, regular incontinence care is pertinent in order to avoid the development of UTI and sepsis (proper hydration can minimize the risk of a UTI from developing as well). Lastly, regular meals that are pureed are effective for the stroke patient. Additional strategies such as placing the food far back in the tongue and drinking of thickened fluid are useful in the prevention of pneumonia if the patient suffers from dysphagia.

Further research is required to determine if such interventions are effective for other stroke patients.

\section{Conflict of Interest}

The author reports no conflict of interest in the writing of this manuscript.

\section{References}

1. Kumlien S, Axelsson K. Stroke patients in nursing homes: eating, feeding, nutrition and related care. Journal of Clinical Learning. 2002; 11: 498-509. doi: 10.1046/j.1365-2702.2002.00636.x

2. Dennis M. Nutrition after stroke. British Medical Bulletin. 2000; 56(2): 46675.

3. Doggett DL, Tappe KA, Mitchell MD, Chapell R, Coates V, et al. Prevention of pneumonia in elderly stroke patient by systematic diagnosis and treatment of dysphagia: an evidence-based comprehensive analysis of the literature. Dysphagia. 2001; 16: 279-95. doi: 10.1007/s00455-0010087-3

4. Spence DJ. Nutrition and stroke prevention. Stroke. 2006; 37(9): 2430-35. doi: 10.1161/01.STR.0000236633.40160.ee

5. Hooper L, Bunn D, Jimoh FO, Fairweather-Tait SJ. Water-loss dehydration and aging. Mechanisms of Aging and Development. 2014; 136-37: 50-58. doi: 10.1016/j.mad.2013.11.009

6. Rowat A, Graham C, Dennis M. Dehydration in hospital-admitted stroke patients. Stroke. 2012; 43: 857-59. doi: 10.1161/STROKEAHA.111.640821

7. Finestone HM, Foley NC, Woodbury MG, Greene-Finestone L. Quantifying fluid intake in dysphagic stroke patients: A preliminary compariswn of oral and non-oral strategies. Archives of Physical Medicine and Rehabilitation. 2001; 82(12): 1744-46. doi: 10.1053/apmr.2001.27379

8. Whelan K. Inadequate fluid intakes in dysphagic acute stroke. Clinical Nutrition. 2001; 20(5): 423-28. doi: 10.1054/clnu.2001.0467

9. Godfrey H, Cloete J, Dymond E, Long A. An exploration of the hydration care of older pepople: A qualitative study. .Int J Nurs Stud. 2012; 49(10): 1200-11. doi: 10.1016/j.jnurstu.2012.04.009

10. Carr EK, Kenney FD. Positioning of the stroke patient: a review of the literature. International Journal of Nursing Studies. 1992; 29(4): 355-69. doi: 10.1016/0020-7489(92)90014-8

11. Brenner I, Stroke-induced hemiplegia: A case report promoting physical activity at home. Annals of Nursing and Practice. 2017; 4(4): 1088. 